www.nature.com/pj

\title{
Effects of ultrasound on the morphology and properties of propylene-based plastomer/nanosilica composites
}

\author{
Bo Peng ${ }^{1}$, Hong $\mathrm{Wu}^{1}$, Wenting Bao ${ }^{1}$, Shaoyun Guo ${ }^{1}$, Yong $\mathrm{Chen}^{2}$, Hua Huang ${ }^{2}$, Hongyu Chen ${ }^{2}$, Shih-Yaw Lai ${ }^{2}$ \\ and Jinder Jow ${ }^{3}$
}

Propylene-based plastomer/nanosilica composites, with a filler content of $1-4 \mathrm{wt} \%$, were prepared by a specially designed ultrasound-assisted extrusion system that was developed in our laboratory. The effects of ultrasound on the morphology, as well as the rheological and mechanical properties of the composites, were studied in this paper. In spite of slight ultrasound-induced degradation of the polymeric matrix, the results showed that the strength and elongation of the composites at break, in most cases, still improve in the presence of ultrasound because of ultrasound-induced homogeneous dispersion of nanoparticles in the polymeric matrix (as confirmed by scanning electron microscope, transmission electron microscope and differential scanning calorimetry studies). Dynamic rheological measurements also indicate that ultrasound-induced compatibilization has a more predominant role than does degradation. From dynamic mechanical measurements, it was found that ultrasound-induced degradation results in a drop in the dynamic storage modulus and glass transition temperature for composites with $\mathbf{4}$ wt\% filler content, whereas ultrasound-induced compatibilization enhances their loss factor values.

Polymer Journal (2011) 43, 91-96; doi:10.1038/pj.2010.95; published online 3 November 2010

Keywords: extrusion; morphology; polymer-matrix composites (PMCs); properties; ultrasound

\section{INTRODUCTION}

In recent years, polymer/inorganic nanocomposites, in which the size of the dispersed particles is $<100 \mathrm{~nm}$ in at least one dimension, have attracted tremendous interest in both academic and industrial researchers. Many studies report significant improvement in the desired properties of nanocomposites, such as their mechanical properties, barrier properties, optical transparency and solvent/heat resistance, compared with those of bulk polymers or conventional microcomposites. ${ }^{1-3}$ These improvements can be achieved at a very low loading of the inorganic component (1-10 wt\%) compared with conventional filled polymers, which require high loading (25-40 wt\%). These studies indicate that polymer/inorganic nanocomposites are much lighter in weight and easier to process than conventional microcomposites. ${ }^{4}$

To a large extent, improvement in these properties depends on the morphology and dispersion of the nanoparticles in the matrix. However, obtaining a homogeneous dispersion of nanoparticles in a polymeric matrix is a very difficult task when using only a simple mixing method, because of the strong tendency of nanoparticles to agglomerate. To break down the agglomerates of nanoparticles, many researchers have attempted various routes to prepare nanostructural composites in recent years, such as the sol-gel process, ${ }^{5}$ in situ intercalative polymerization ${ }^{6,7}$ and in situ polymerization in the presence of nanoparticles. ${ }^{8}$ These methods, characterized by complex polymerization and special conditions, are not only incompatible with current industrial processes such as extrusion and injection molding, but are also inapplicable for the mass production of polymer/inorganic nanocomposites. In view of the cost-effectiveness and feasibility of the available processing techniques, melt blending of polymers with nanoparticles is still the optimum method of compounding. To achieve homogeneous dispersions of nanoparticles in polymeric matrices and to enhance the interactions between fillers and polymer matrices during the melt-blending process, several methods are generally applied: ${ }^{4,9-13}$ (1) the surface modification of nanoparticles with coupling agents or active monomers; (2) the polar group functionalization of polymers with partial oxidation, $\gamma$-rays, electron beams, microwaves, UV irradiation or polar grafting; (3) the addition of a bifunctional component (compatibilizer) that can interact with both fillers and polymer matrices; and (4) the mechanochemical modification of nanoparticles.

In addition, power ultrasound is a clean, efficient and attractive oscillation technology that has been applied to the melt-blending process of polymer/inorganic nanocomposites. Additional local molecular vibration is produced under ultrasound to better promote dispersion of nanoparticles in a polymeric matrix or better intercalation and exfoliation of clay. Relevant studies are largely focused on

\footnotetext{
${ }^{1}$ The State Key Laboratory of Polymer Materials Engineering, Polymer Research Institute, Sichuan University, Chengdu, PR China; ${ }^{2}$ The Dow Chemical (China) Company Limited, Shanghai, PR China and ${ }^{3}$ The Dow Chemical Company Limited, Freeport, TX, USA

Correspondence: Professor H Wu or Professor S Guo, The State Key Laboratory of Polymer Materials Engineering, Polymer Research Institute, Sichuan University, 24, South Section 1,Yihuan Road, Chengdu, Sichuan 610065, PR China.

E-mail: wh@scu.edu.cn or nic7702@scu.edu.cn

Received 3 July 2010; revised 27 August 2010; accepted 1 September 2010; published online 3 November 2010
} 
polymer/layered clay systems. ${ }^{14-18}$ However, very few works are devoted to research on polymer-filled, non-layered inorganic nanoparticles. In the current work, a special single screw extruder equipped with an ultrasound generator was used to compound a novel propylene-based plastomer with nanosilica. Here, propylene-based plastomers, called 'Developmental Plastomers' (DP) by the Dow Chemical Company, are a versatile family of propylene-ethylene copolymers, greatly different from both Ziegler-Natta and metallocene catalyst-based copolymers of propylene. Their characteristics have already been described in our previous works. ${ }^{19,20}$ Here, the ultrasound-assisted extrusion processing is expected to achieve a more effective breakup of the particle agglomerates in the absence of solvent and chemicals, thus yielding useful polymer/non-layered inorganic nanocomposites. The effects of ultrasound on the morphology, as well as the rheological and mechanical properties of the composites, are also discussed in detail.

\section{EXPERIMENTAL PROCEDURE}

\section{Materials and equipment}

DP was supplied in pellet form by Dow Chemical Co. (Freeport, TX, USA). It had a melt flow index of $5.0 \mathrm{~g}$ per $10 \mathrm{~min}\left(2.16 \mathrm{~kg}\right.$ at $\left.230^{\circ} \mathrm{C}\right)$ and a density of $0.888 \mathrm{~g} \mathrm{~cm}^{-3}$. Nano-SiO ${ }_{2}$ with an average primary particle size of $20 \mathrm{~nm}$ was purchased from Hongsheng Technology Co., Ltd. (Zhoushan, China). The main processing equipment used was a specially designed ultrasound-assisted extrusion system developed in our laboratory, and the schematic diagram and working principle were described in our previous work. ${ }^{21}$ The maximum power output and fixed frequency of the ultrasound were $300 \mathrm{~W}$ and $20 \mathrm{kHz}$, generated by a piezoelectric transducer. The oscillation of the ultrasound was in the direction parallel to the flow of the polymer melt.

\section{Composite preparation}

$\mathrm{DP}$ and nano- $\mathrm{SiO}_{2}$ were premixed and then fed into the ultrasonic ultrasoundassisted extruder. The processing temperatures at different zones, from the hopper to the die, were fixed at $110,160,160$ and $160^{\circ} \mathrm{C}$. The screw rotation speed was 5 r.p.m. The extrudates were palletized and then compression molded into 1-mm-thick plates at a pressure of $12 \mathrm{MPa}$ and a temperature of $160^{\circ} \mathrm{C}$ to obtain specimens for further measurements and characterization.

\section{Measurements and characterization}

Tensile testing of the composites was conducted with dumbbell-shaped samples on an Instron 4302 tension machine (Instron, Canton, MA, USA) with a crosshead speed of $500 \mathrm{~mm} \mathrm{~min}^{-1}$ at room temperature. The size of the narrow section of the samples was $25 \times 4 \times 1 \mathrm{~mm}^{3}$. The reported values of strength and elongation at break are the average value taken from five tests.

The morphology of the dispersed phase in the polymer matrix was investigated using a JSM-5900 LV scanning electron microscope (SEM) manufactured by JEOL Co. (JEOL, Tokyo, Japan) at an accelerating voltage of $20 \mathrm{kV}$ and a Tecnai-20 transmission electron microscope (TEM) manufactured by FEI Co. (Hillsboro, OR, USA) at an acceleration voltage of $200 \mathrm{kV}$. The samples for SEM were fractured in liquid nitrogen and coated with gold before observation, and those for TEM were taken from ultrathin sections of the composites.

Dynamic rheological measurements were taken using a Gemini 200 (Malvern Co., Worcestershire, UK) dynamic stress rheometer in an air atmosphere with $25-\mathrm{mm}$ parallel plate geometry and a $1-\mathrm{mm}$ sample gap. The dynamic frequency sweep tests were executed in the frequency range of $0.025-0.3 \mathrm{~Hz}$ at $160^{\circ} \mathrm{C}$ with a strain amplitude of $2 \%$, in which the rheological behavior was in the linear viscoelastic range.

Dynamic mechanical analysis was performed with a DMA Q800 instrument (TA Co., Boston, MA, USA) to measure the loss factor $\tan \delta$ and storage modulus $E^{\prime}$ over the temperature range from -50 to $100{ }^{\circ} \mathrm{C}$ at a constant frequency of $10 \mathrm{~Hz}$ and a small strain region of $0.2 \%$ using specimens of $17 \times 7 \times 1 \mathrm{~mm}^{3}$ dimensions in the tensile mode. The heating rate was $5{ }^{\circ} \mathrm{C} \mathrm{min}{ }^{-1}$.

Differential scanning calorimetry analysis was carried out by a differential thermal analyzer 2100 (Dupont Co., Parkersburg, WV, USA). Samples were heated from room temperature to $150{ }^{\circ} \mathrm{C}$ at a rate of $10^{\circ} \mathrm{Cmin}^{-1}$ and kept at this temperature for $5 \mathrm{~min}$. They were then cooled to room temperature. All samples were kept under nitrogen while cooling curves were recorded.

\section{RESULTS AND DISCUSSION}

\section{Tensile properties}

The dependence of the strength at break of the DP/nano- $\mathrm{SiO}_{2}$ composites on the $\mathrm{SiO}_{2}$ content with various amounts of ultrasound power is shown in Figure 1. Without nanosilica, no significant difference in the tensile strength at break was observed with or without ultrasound power up to $200 \mathrm{~W}$. This observation suggests that the slight change in molecular weight reported in our previous work ${ }^{20}$ does not have a significant impact on the tensile strength. When nanosilica is added to DP in the absence of ultrasound during extrusion, an increase in the strength at break is measured up to $2 \mathrm{wt} \%$, whereas there is a decreasing trend in the strength at break with an increase in silica content up to $4 \%$. It should be attributed to the poor dispersion and interface adhesion of nanoparticles in the DP matrix at a high filler content. When ultrasound is introduced into the melt of the composites during extrusion, it helps to reduce the size of the $\mathrm{SiO}_{2}$ nanoparticle agglomerate. Thus, the strength at break improves in most cases, except those at the 1 or $2 \%$ filler content under $200 \mathrm{~W}$. SEM, TEM and differential scanning calorimetry analyses will be used to confirm these claims. However, for DP/nano- $\mathrm{SiO}_{2}$ composites, $200 \mathrm{~W}$ ultrasound conversely decreased the strength at break of the composites at $1 \%$ filler content and showed no difference in tensile strength at $2 \%$ filler content.

Ultrasound provides the local molecular vibration to disentangle polymer chains and slightly reduce the molecular weight, both of which improve the filler dispersion. Increasing the ultrasound power level or the filler level is expected to increase the local power density in the polymer matrix and result in a more mechanochemical degradation that can provide a greater reduction in tensile strength. Therefore, ultrasound-induced dispersion of nanoparticles (that is, compatibilization) and degradation of the polymeric matrix are two competitive mechanisms, together resulting in a final value of the strength at break for the composites. When the nanofiller content is relatively low, its distribution in the polymeric matrix is easily determined; thus, the degradation of the polymeric matrix using high-power ultrasound may be detrimental to the mechanical properties of the composites.

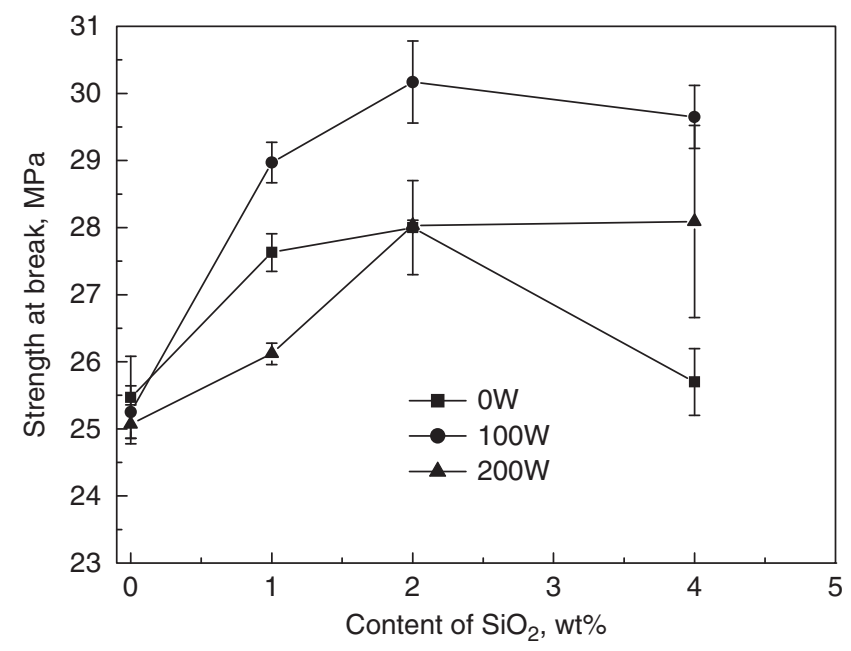

Figure 1 Dependence of strength at break of DP composites filled with $\mathrm{SiO}_{2}$ on the $\mathrm{SiO}_{2}$ content with various ultrasound power values. 
However, when the filler content further increases, the nanoparticles are apt to agglomerate. Thereby, ultrasound-induced compatibilization has the more predominant effect on the strength at break of the composites compared with ultrasound-induced degradation. From Figure 2, using a 'mild' power $(100 \mathrm{~W})$ of ultrasound in our experiment seems more beneficial for enhancing the strength at break of the composites, even in chemically untreated nanoparticle-filled systems.

In addition, although the values of the elongation at break measured in this work have considerable deviations (Figure 2), the

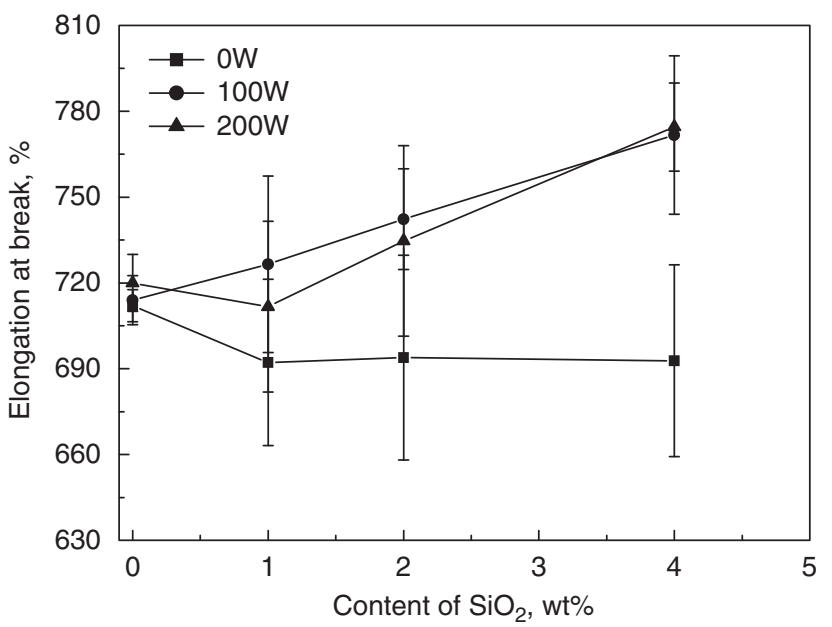

Figure 2 Dependence of elongation of DP composites filled with $\mathrm{SiO}_{2}$ at break on the $\mathrm{SiO}_{2}$ content with various ultrasound power values. results show a decreasing trend in elongation at break of DP by adding nano- $\mathrm{SiO}_{2}$ in the absence of ultrasound, implying that the fillers cause a reduction in matrix deformation because of the introduction of mechanical restraints. On the other hand, the decline in the elongation at break of $\mathrm{DP} /$ nano- $\mathrm{SiO}_{2}$ composites can be inhibited, and even the elongation at break increases with different degrees, by the aid of ultrasound-induced compatibilization during extrusion, especially for composites with a high filler content.

\section{Morphology}

Figure 3 presents SEM micrographs of the fractured surfaces of DP/ nano- $\mathrm{SiO}_{2}(96 / 4)$ composites. In the absence of ultrasound, large and stacked $\mathrm{SiO}_{2}$ nanoparticles $(\sim 1 \mu \mathrm{m})$ can be observed on the fractured surfaces of the composites. However, the $\mathrm{SiO}_{2}$ nanoparticles become smaller and the aggregation $(\sim 1 \mu \mathrm{m})$ of the $\mathrm{SiO}_{2}$ nanoparticles disappears because of the $100-\mathrm{W}$ ultrasound. In addition, a more homogeneous dispersion of $\mathrm{SiO}_{2}$ nanoparticles into DP matrix is achieved. As shown in Figure 4, TEM micrographs further demonstrate the effect of ultrasound on the morphology of $\mathrm{DP} /$ nano- $\mathrm{SiO}_{2}$ composites. When the composite melts flow into the ultrasound effect zone (that is, the die of the extruder), both the powerful vibration and the shatter of ultrasound lead to the disentanglement, and even scission, of macromolecular chains, and at the same time, they help to reduce the size of the agglomerates of $\mathrm{SiO}_{2}$ nanoparticles and disperse them evenly in the DP matrix.

\section{Dynamic rheological properties}

The logarithm curves of dynamic rheological parameters, including the elastic modulus $\left(G^{\prime}\right)$, viscous modulus $\left(G^{\prime \prime}\right)$ and complex viscosity
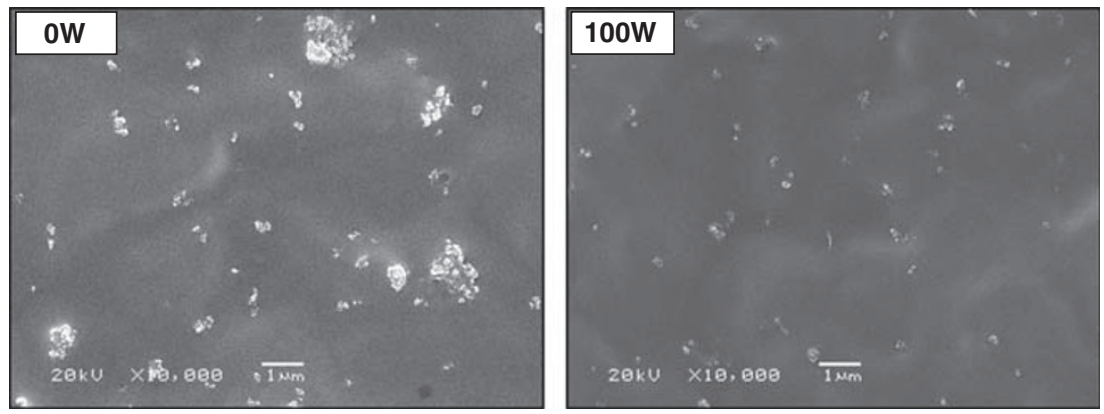

Figure 3 Effect of ultrasound on SEM micrographs for DP/nano-SiO 2 (96/4) composites.
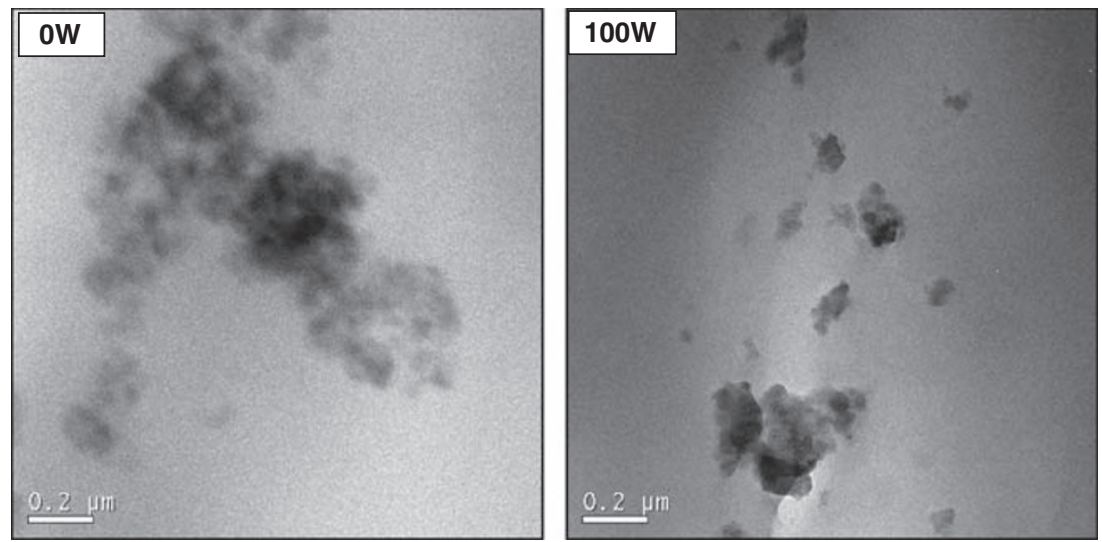

Figure 4 Effect of ultrasound on TEM micrographs for $\mathrm{DP} / \mathrm{nano}-\mathrm{SiO}_{2}(96 / 4)$ composites. 

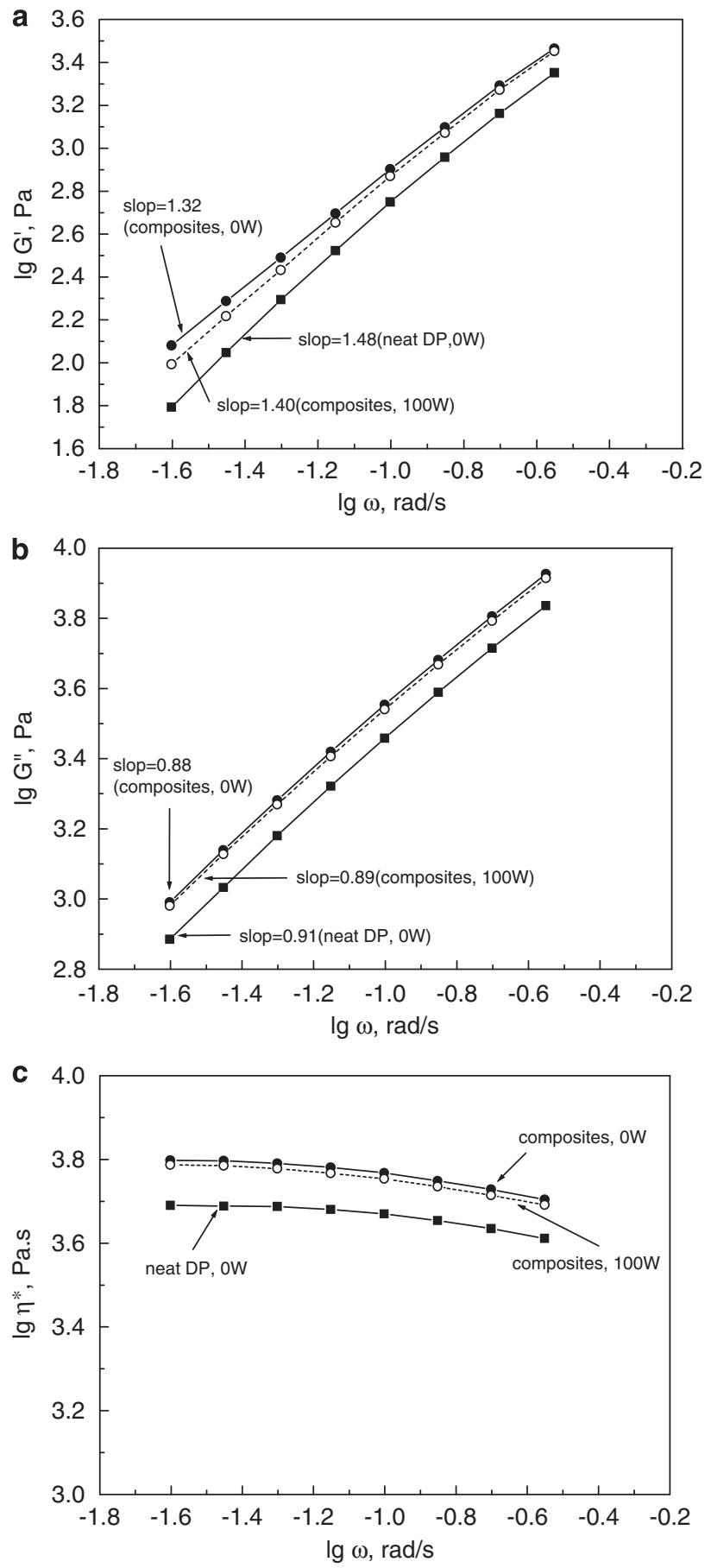

Figure 5 Dynamic rheological parameters, including (a) $G^{\prime}$, (b) $G^{\prime \prime}$ and (c) $\eta^{*}$, versus $\omega$ for $\mathrm{DP}$ and $\mathrm{DP} /$ nano-SiO 2 (96/4) composites in the absence and presence of ultrasound.

$\left(\eta^{*}\right)$, versus the angular frequency $(\omega)$ of the DP and DP/nano- $\mathrm{SiO}_{2}$ (96/4) composites in the low frequency zone are shown in Figures $5 \mathrm{a}-\mathrm{c}$. As expected, the addition of nano- $\mathrm{SiO}_{2}$ into the DP matrix results in an increase in $G^{\prime}, G^{\prime \prime}$ and $\eta^{*}$. Conversely, the 100-W ultrasound applied during extrusion decreases the linear viscoelastic parameters of the composites. Ultrasound-induced dispersion of nanoparticles and degradation of the polymeric matrix can jointly determine the reduction. ${ }^{12,19,22}$ According to the linear viscoelastic theory, the slopes of $\lg G^{\prime}-\lg \omega$ and $\lg G^{\prime \prime}-\lg \omega$ in the terminal zone (that is, the low-frequency zone) are closely related to the variation in the polydispersity of the polymer matrix and the composite morphology. ${ }^{23-26}$ In general, as the width of the molecular weight distribution increases, the slopes decrease. Previously mentioned in our work, ${ }^{19,20}$ the molecular weight distribution of neat DP increases, whereas its molecular weight decreases in the presence of ultrasound, indicating a decrease in the slopes of $\lg G^{\prime}-\lg \omega$ and $\lg G^{\prime \prime}-\lg \omega$. On the other hand, the better compatibility and more uniform dispersion of the particles in the polymeric matrix are beneficial and are shown by the rise in the slopes of $\lg G^{\prime}-\lg \omega$ and $\lg G^{\prime \prime}-\lg \omega$. As shown by the slopes marked in Figures $5 \mathrm{a}$ and $\mathrm{b}$, the addition of nano- $\mathrm{SiO}_{2}$ into the DP matrix reduces the slope values of DP. A similar phenomenon can be observed in most particle-filled systems. ${ }^{27,28}$ It is interesting that the slopes of composites increase with the introduction of ultrasound, which can be interpreted only by the fact that the effect of ultrasound-induced compatibilization on dynamic rheological properties is more significant than ultrasound-induced degradation.

\section{Dynamic mechanical properties}

Figures $6 \mathrm{a}$ and $\mathrm{b}$ depict the dynamic mechanical spectra (dynamic storage modulus $E^{\prime}$ and loss factor $\tan \delta$ ) as a function of temperature for $\mathrm{DP}$ and $\mathrm{DP} /$ nano- $\mathrm{SiO}_{2}(96 / 4)$ composites in the absence and presence of $100-\mathrm{W}$ ultrasound. Results clearly show that, in the absence of ultrasound, the addition of nano- $\mathrm{SiO}_{2}$ particles into the DP matrix increases the $E^{\prime}$ values while decreasing the $\tan \delta$ values, indicating improved stiffness and deteriorative ductility of DP. The increase in stiffness is a result of the high modulus of nanosilica $(70 \mathrm{GPa})$, whereas the reduction of ductility should be ascribed to the above-mentioned congregation of nano- $\mathrm{SiO}_{2}$ particles. At the same time, all samples (Figure 6b) present a dispersive peak in the temperature range studied, which is attributed to the micro-Brownian motion of macromolecular chains in the amorphous phase of the DP matrix. The peak temperature is the glass transition temperature $(T g)$, the value of which is also marked in Figure 6b. Neat DP has a $\mathrm{Tg}$ of $12.4^{\circ} \mathrm{C}$, whereas $4 \mathrm{wt} \%$ filler loading decreases it to $11.3^{\circ} \mathrm{C}$. Liuet al. ${ }^{29}$ obtained similar results in polypropylene/layered silicate nanocomposites.

With the introduction of ultrasound, the values of $E^{\prime}$ and $T g$ of the composites decreased, indicating a decrease in stiffness for the composites and an enhancement in the mobility for the DP chain segment. All these observations should be attributed to either the decreased molecular weight of DP or the disentangled polymer chains, both of which were induced by ultrasound. Simultaneously, ultrasound-induced degradation of the DP matrix results in an increase in $\tan \delta$ values. ${ }^{20}$ In addition, a more uniform dispersion of nanoparticles in the presence of ultrasound increases the effective volume fraction of the filler in the DP matrix and conclusively enhances the dissipation capability of particle-filled systems to exterior energy. It also benefits the increase in $\tan \delta$ values of the composites.

\section{Crystallization properties}

Figure 7 shows the cooling curves of DP and DP/nano- $\mathrm{SiO}_{2}(96 / 4)$ composites, and the data describing crystallization temperature $\left(T_{c}\right)$ and enthalpy $\left(\Delta H_{c}\right)$ are listed in Table 1 . These data show that the addition of nano- $\mathrm{SiO}_{2}$ can lead to the heterogeneous nucleation of DP at a higher temperature and to the increase in the crystallization temperature. The crystallization temperature of DP in composites is enhanced further because of the presence of $100-\mathrm{W}$ ultrasound, indicating that ultrasound is helpful to the distribution of nano$\mathrm{SiO}_{2}$ in the DP matrix. As the filler dispersion increases, the interfacial 

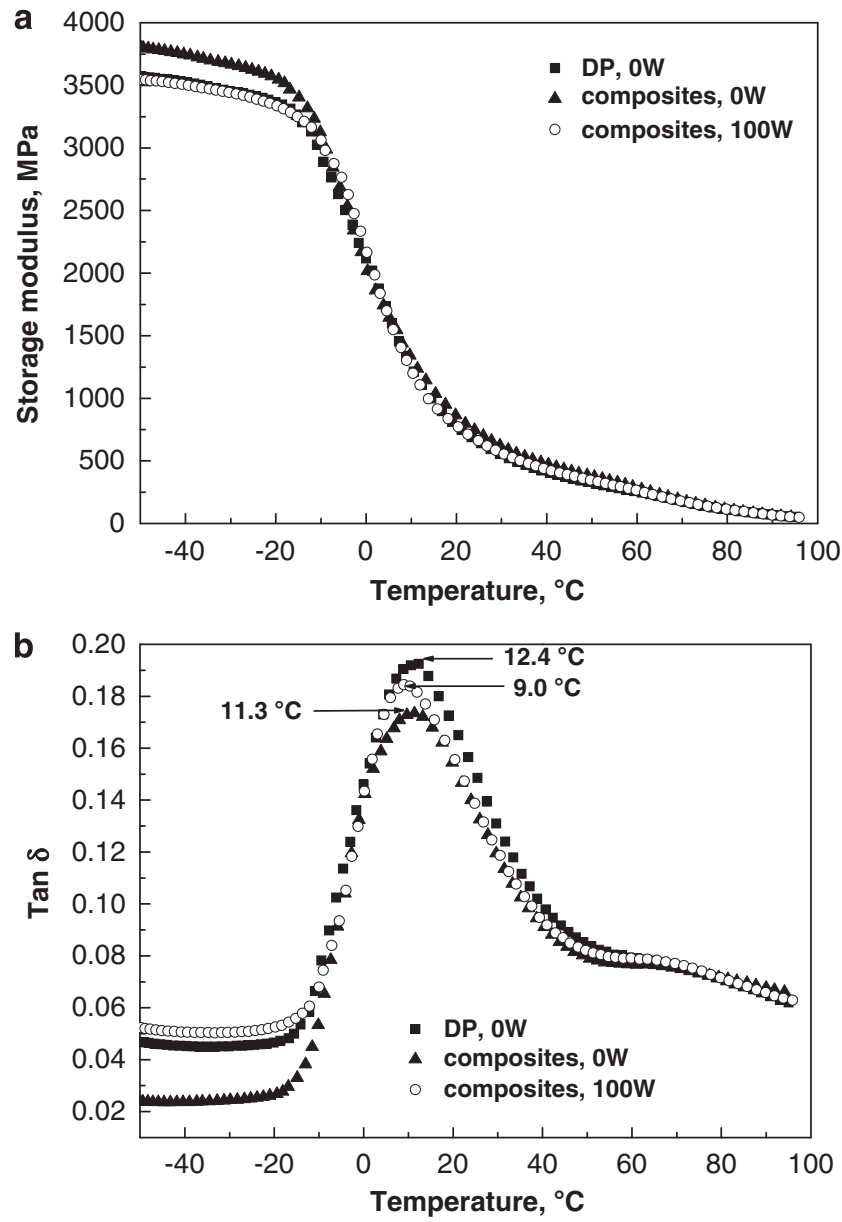

Figure 6 DMA traces of (a) storage modulus and (b) loss factor versus temperature for $\mathrm{DP}$ and $\mathrm{DP} /$ nano- $\mathrm{SiO}_{2}(96 / 4)$ composites in the absence and presence of ultrasound.

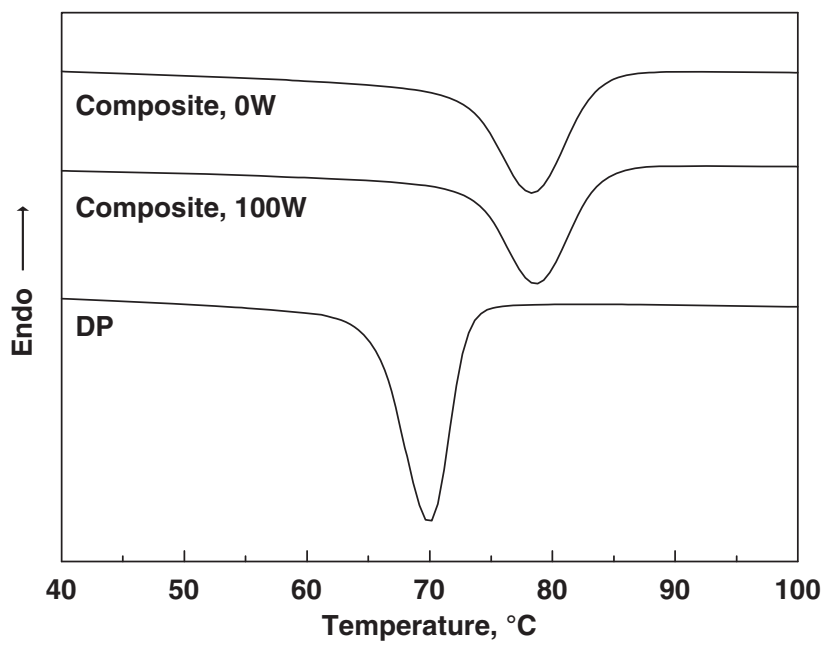

Figure 7 Differential scanning calorimetry cooling curves of DP and composites.

interaction strengthens, and the nucleation becomes more obvious. Further, the addition of nano- $\mathrm{SiO}_{2}$ can reduce the crystallization enthalpy of DP because the movement of the molecular chain of
Table 1 DSC data of the samples

\begin{tabular}{lccc}
\hline Samples & Composites, & Composites, \\
& $D P$ & OW ultrasound & 100 W ultrasound \\
\hline$T_{c},{ }^{\circ} \mathrm{C}$ & 69.9 & 78.3 & 78.6 \\
$\Delta H_{c}, \mathrm{Jg}^{-1}$ & 55.0 & 53.2 & 45.1 \\
\hline
\end{tabular}

Abbreviations: DP, Developmental Plastomers; DSC, differential scanning calorimetry; $\Delta H_{c}$ enthalpy; $T_{c}$, crystallization temperature.

DP is limited by the filler, and the crystal becomes more imperfect. It becomes more obvious when a $100-\mathrm{W}$ ultrasound is applied to the composite.

\section{CONCLUSIONS}

In this paper, $\mathrm{DP} /$ nano- $\mathrm{SiO}_{2}$ composites with a filler content of $1-4 \mathrm{wt} \%$ were prepared through an ultrasound-assisted extrusion at $160{ }^{\circ} \mathrm{C}$. Ultrasound-induced homogeneous dispersion of nanoparticles in a polymeric matrix, as confirmed by SEM and TEM studies, as well as by ultrasound-induced compatibilization, can overcome the negative influence stemming from the ultrasound-induced degradation of the polymeric matrix. Thus, the strength and elongation at break (under conditions of a larger strain region) of the composites improved in most cases. With the introduction of ultrasound, an increase in the slopes of $\lg G^{\prime}-\lg \omega$ and $\lg G^{\prime \prime}-\lg \omega$ for the composites with $4 \mathrm{wt} \%$ filler content also indicates that the effect of ultrasoundinduced compatibilization is dominant, along with the decrease in the values of $G^{\prime}, G^{\prime \prime}$ and $\eta^{*}$. Nevertheless, ultrasound-induced degradation can result in a drop in the dynamic storage modulus $E^{\prime}$ (under conditions of a smaller strain region) and the glass transition temperature $\mathrm{Tg}$ for the composites with $4 \mathrm{wt} \%$ filler content. Together with the ultrasound-induced compatibilization, both result in the enhancement of the loss factor, $\tan \delta$. Finally, the results of differential scanning calorimetry also show that ultrasound is helpful in the distribution of nano- $\mathrm{SiO}_{2}$ in the DP matrix.

\section{ACKNOWLEDGEMENTS}

This study was supported by the Dow Chemical Company (USA) and by Special Funds for Major State Basic Research Projects of China; contract Grant number: 2005CB623800.

1 Giannelis, E. P. Polymer Layered Silicate Nano composites. Adv. Mater. 8, 29-35 (1996).

2 Yano, K., Usuki, A., Yurauchi, T. \& Kamigaito, O. Synthesis and properties of polyimideclay hybrid. J. Polym. Sci. Part A: Polym. Chem. 31, 2493-2498 (1993).

3 Kawasumi, M., Hasegawa, N., Kato, M., Usuki, A. \& Okada, A. Preparation and mechanical properties of polypropylene-clay hybrids. Macromolecules 30, 6333-6338 (1997).

4 Rong, M., Zhang, M., Zheng, Y., Zeng, H., Walter, R. \& Friedrich, K. Structure-property relationships of irradiation grafted nano-inorganic particle filled polypropylene composites. Polymer 42, 167-183 (2001).

5 Chen, Y. \& Iroh, J. O. Synthesis and Characterization of Polyimide/Silica Hybrid Composites. Chem. Mater. 11, 1218-1222 (1999).

6 Usuki, A., Kojima, Y., Kawasumi, M., Okada, A., Fukushima, Y., Kuroachi, T. \& Kaimigato, O. Synthesis of nylon 6-clay hybrid. J. Mater. Res. 8, 1179-1184 (1993).

7 Wang, M. S. \& Pinnavaia, T. J. Clay-Polymer Nanocomposites Formed from Acidic Derivatives of Montmorillonite and an Epoxy Resin. Chem. Mater. 6, 468-474 (1994).

8 Yang, F., Ou, Y. \& Yu, Z. Polyamide 6/silica nanocomposites prepared by in situ polymerization. J. Appl. Polym. Sci. 69, 335-341 (1998).

9 Rong, M Z., Zhang, M. Q., Pan, S. \& Friedrich, K. Interfacial effects in polypropylenesilica nanocomposites. J. Appl. Polym. Sci. 92, 1771-1781 (2004).

10 Wang, G., Chen, X. Y., Huang, R. \& Zhang, L. Nano-CaCO $3 /$ polypropylene composites made with ultra-high-speed mixer. J. Mater. Sci. Lett. 21, 985-986 (2002).

11 Nam, P. H., Maiti, P., Okamoto, M. \& Kotaka, T. A hierarchical structure and properties of intercalated polypropylene/clay nanocomposites. Polymer 42, 9633-9640 (2001). 
12 Li, Y., Chen, G., Guo, S. \& Li, H. Effect of ultrasonic oscillations on the rheological behavior and morphology of Illite-filled high-density polyethylene composites. J. Appl. Polym. Sci. 96, 379-384 (2005).

13 Xiong, Y., Chen, G. \& Guo, S. The preparation of core-shell $\mathrm{CaCO} 3$ particles and its effect on mechanical property of PVC composites. J. Appl. Polym. Sci. 102, 1084-1091 (2006).

14 Ryu, J. G., Park, S. W., Kim, H. \& Lee, J. W. Power ultrasound effects for in situ compatibilization of polymer-clay nanocomposites. Mater. Sci. Eng. C. 24, 285-288 (2004).

15 Lee, E. C., Mielewski, D. F. \& Baird, R. Exfoliation and dispersion enhancement in polypropylene nanocomposites by in-situ melt phase ultrasonication. J. Polym. Eng. Sci. 44, 1773-1782 (2004).

16 Ryu, J. G., Kim, H. \& Lee, J.W. Characteristics of polystyrene/polyethylene/clay nanocomposites prepared by ultrasound-assisted mixing process. J. Polym. Eng. Sci. 44, 1198-1204 (2004).

$17 \mathrm{Li}$, J., Zhao, L. \& Guo, S. Ultrasonic Preparation of Polymer/Layered Silicate Nanocomposites during Extrusion. Polym. Bull. 55, 217-223 (2005).

18 Zhao, L., Li, J., Guo, S. \& Du, Q. Ultrasonic oscillations induced morphology and property development of polypropylene/montmorillonite nanocomposites. Polymer 47, 2460-2469 (2006).

19 Peng, B., Wu, H., Guo, S., Lai, S. Y. \& Jow, J. Static ultrasonic oscillations induced degradation and its effect on the linear rheological behavior of novel propylene based plastomer melts. J. Polym. Degrad. Stab. 92, 1632-1639 (2007).
20 Peng, B., Wu, H., Guo, S., Lai, S. Y. \& Jow, J. Effects of ultrasonic oscillations on rheological behavior and mechanical properties of novel propylene-based plastomers. J. Appl. Polym. Sci. 106, 1725-1732 (2007).

21 Chen, G. S., Guo, S. Y. \& Li, H. L. Ultrasonic improvement of rheological behavior of polystyrene. J. Appl. Polym. Sci. 84, 2451-2460 (2002).

22 Li, J., Liang, M., Guo, S., Kuthanova, V. \& Hausnerova, B. Linear viscoelastic properties of high-density polyethylene/polyamide- 6 blends extruded in the presence of ultrasonic oscillations. J. Polym. Sci. Pol. Phys. 43, 1260-1269 (2005).

23 Han, C. D. \& Kim, J. K. Rheological technique for determining the order-disorder transition of block copolymers. J. Polym. Sci. Pol. Phys. 25, 1741-1764 (1987).

24 Han, C. D. \& Kim, J. K. Molecular theory for the viscoelasticity of compatible polymer mixtures. 2. Tube model with reptation and constraint release contributions. Macromolecules 22, 4292-4302 (1989).

25 Zheng, Q., Yang, B., Wu, G. \& Li, L. A Study of Dynamic Rheology for Multicomponent Polymers. Chem. J. Chinese U. 20, 1483-1485 (1999).

26 Chen, C., Zheng, Q. \& Hu, H. Effect of Filler Surface-Treatment on Dynamic Viscoelastic Properties for PMVS/SiO2 Composites. Chem. J. Chinese U. 25, 1969-1971 (2004).

$27 \mathrm{Hu}, \mathrm{H}$., Chen, C. \& Zheng, Q. Dynamic Rheological Properties of Poly(methyl vinyl) siloxane Filled with Untrafine Porous Silica. Chem. J. Chinese U. 25, 985-987 (2004).

28 Dong, Q., Zheng, Q. \& Du, M. Dynamic Rheological Behavior of Particles-filled HDPE Composite Systems. M. Chem. J. Chinese U. 26, 1761-1764 (2005).

29 Liu, X. \& Wu, Q. PP/clay nanocomposites prepared by grafting-melt intercalation. Polymer 42, 10013-10019 (2001). 